\title{
Investigations of the through-thickness residual stress distribution during the partial heating roll forming process of square and rectangular hollow steel sections
}

\author{
Zelalem Abathun Mehari ${ }^{1}$ and Jingtao $\operatorname{Han}^{1}$ \\ ${ }^{1}$ University of Science and Technology Beijing
}

December 17, 2021

\begin{abstract}
With the growing demand for rectangular and square hollow steel sections in the last few decades, the cold roll forming process has become a widely acknowledged hollow sections manufacturing method; however, residual stress generated during the roll forming process is one of the primary concerns on roll-formed products. In this regard, several researchers have conducted numerical and experimental investigations of residual stress distributions on roll-formed steel sections. However, most of the studies found in the literature have been confined to the measurement of residual surface stresses. On the other hand, experimental studies conducted on fatigue and load-carrying capacity of hollow structural steels have shown that there is indeed a simple relation between the through-thickness residual stress distributions and mechanical properties of structures. Thus, this paper employed a proper numerical modelling procedure using LS-DYNA's finite element code to explore throughthickness residual stress distributions generated during the roll forming process of rectangular and square hollow steel sections from different material grades. Moreover, a small-scale parametric study was conducted to explore the effects of the partial heating roll forming method on through-the-thickness residual stress distributions to satisfy the growing demand for residual stress-free roll-formed products.
\end{abstract}

\section{Hosted file}

Manuscript.docx available at https://authorea.com/users/451545/articles/549772investigations-of-the-through-thickness-residual-stress-distribution-during-the-partialheating-roll-forming-process-of-square-and-rectangular-hollow-steel-sections 